\title{
Post-pandemic Pedagogy: Distance Education in Greece During COVID-19 Pandemic Through the Eyes of the Teachers
}

\author{
Stefanos Nikiforos, Spyros Tzanavaris, and Katia Lida Kermanidis
}

\begin{abstract}
Distance education had already appeared since 1970. During the first implementation period it mainly concerned adults and education at university level. In the recent years, through the internet development, distance education has acquired a new hypostasis, as innovative applications have facilitated its implementation in multiple contexts. Despite this, education remained mainly on a physical level (face to face interaction), while distance education was rather complementary (hybrid or blended learning). However, during the COVID-19 pandemic, the first pandemic in the digital era, an urgent need that led to a universal and "violent" transition to distance education arose, often without assuring the necessary preconditions. This research aims to capture the experience of teachers in Greece during this transition.
\end{abstract}

Index Terms - Distance education, COVID-19, pandemic, lockdown, teachers' experience

\section{INTRODUCTION}

Pandemic diseases have appeared many times in the world history. From Galen of Pergamon who battled smallpox -"the great plague" or "the long plague"- in 166 $\mathrm{AD}$, to the recently $2009 \mathrm{H} 1 \mathrm{~N} 1$ swine flu pandemics. The current COVID-19 pandemic was a moment of global digital transformation equalizing social distancing, and in that sense, constituted the first "digital pandemic". As world stayed at home, education went online. Data regarding distance education during the pandemic are still limited. However, this study is based on emerging knowledge and experience during the current pandemic. In this paper preliminary results at the descriptive level from a research concerning 1,120 teachers from primary and secondary education in Greece are presented.

\section{RELATED WORK}

\section{A. Distance Education}

The term "distance education" was used for the first time in the 1970's and was firstly adopted in the 1980's [1]. At first, this type of education mainly concerned adults and universities. Before the COVID-19 pandemic, distance

Published on December 19, 2020.

S. Nikiforos, Humanistic and Social Informatics Laboratory, Department of Informatics, Ionian University, Corfu, Greece.

(e-mail: c13niki@ionio.gr)

S. Tzanavaris, School of Pastoral and Social Theology, Aristotle University of Thessaloniki, Greece.

(e-mail: stzanavaris@ionio.gr)

K. L. Kermanidis, Humanistic and Social Informatics Laboratory, Department of Informatics, Ionian University, Corfu, Greece.

(e-mail: kerman@ionio.gr). learning in primary and secondary Greek schools served complementary to traditional education, forming a schema of hybrid or blended learning. Blended learning is defined as a learning system combining face-to-face instruction with computer mediated instruction [2], that is the asynchronous or synchronous e-learning [3]. Asynchronous distance education allows the combination of participation in group interaction with individual pacing [1]. It is implemented mainly with e-mails, education platforms (Moodle) and wikis, and allows students to study in their own time. Synchronous distance education (videoconferencing) has already been used before the COVID-19 pandemic, e.g. via Skype. The main features for a platform to be chosen are stability, the user friendliness of the interface and security.

Distance education holds an important role in the era of internet, in a variety of disciplines [4]. Although it has appeared in many forms in the past (education by mail or tapes), distance education has emerged radically in the Web 2.0 environment. Students have the ability to learn, regardless of space and time dependencies. Teachers and students do not meet face to face and the learning process is facilitated by media. Communication between the teachers and the students may exist in distance education, while interaction between them or among the peers is not guaranteed. Students are usually taught as individuals and not in groups or learning communities [1]. Interaction mainly exists in terms of one to one relation between the student and the teacher. This type of interaction is accompanied by assignments provided by the teacher to the student. When the student completes the assignments, he submits them to the teacher in order to receive feedback. Nowadays distance education is an important part of global educational activity.

\section{B. Experience from the pandemic}

The H1N1 pandemic (2009) forced some research on Information and Communication Technology - ICT [5] on distance learning. Nevertheless other research on primary and secondary schools focused on social distancing during a long period closure, and not on technology advantage [6][8]. Reference [9] found limited literature on school practices to promote social distancing, as well as limited incorporation of school practices to promote social distancing, among 38 states in the USA. The current COVID-19 pandemic has the peculiarity of closing schools worldwide, thus forcing the use of technology. A wellconsidered virtual continuing education program may enhance knowledge and skills, whilst simultaneously be supportive in many disciplines, during an unprecedented, difficult period [10]. For example, a daily medical education 
procedure set up for surgical students confined to their homes, during COVID-19 [11]. A simple video conference method was applied to clinical and anatomy daily lessons, using the Google Hangouts application. Virtual learning during this pandemic can significantly reshape and innovate teaching, as well as allow the continuation of fostering a sense of community [12].

Although there is no substitute for face to face and handson learning, several innovative solutions, including the flipped classroom model, online practice questions, teleconferencing in place of in-person lectures, procedural simulation and the facilitated use of videos, may constitute ways to mitigate loss of learning during the COVID-19 pandemic [13]. Reference [14] describes best practices raised for enhancing online learning: lessons should be engaging and positive, teachers should be flexible and build connections, learn from other instructors, rethink how learning is assessed and pick the right technology. The learning process in Greece was suspended from the March 10th until May 11th 2020. The alternative in this case was to move from traditional to online education, using the internet, computers or mobile devices. The Ministry of Education suggested Webex (https:/www.webex.com/), a Cisco software, to serve as a synchronous platform and e-me (https://e-me.edu.gr) or e-class (https://eclass.sch.gr/) platforms for asynchronous distance education. The free version of Zoom (https:/www.zoom.us/) and e-mails were also widely used by the teachers.

\section{AIMS AND SCOPE}

The aim of this research was to investigate the experience of the teachers in Greece regarding distance education during the COVID-19 pandemic. Distance education in Greek schools was sparsely implemented. Teachers were not trained to employ e-learning technologies. Although there were training programs for the teachers regarding the utilization of ICT in face to face education, they did not refer to distance education. Infrastructure in schools was usually inadequate. Students had no previous experience in distance learning applications, and their equipment was often inadequate. Internet connection for both the teachers and the students was usually poor, or non-existing. Under these circumstances educational community in Greece faced the challenge of a sudden and "violent" transition to distance education.

In this context, the current research attempts to answer the following research question: what was the experience of the teachers in Greece regarding distance learning during the COVID-19 pandemic?

Preliminary descriptive results are presented in this paper. In depth analysis results regarding correlations between variables will be explored in the next step of the research.

\section{A. Data collection}

A questionnaire consisting of twenty seven questions was constructed. During the first phase of the research a pilot questionnaire was implemented. Ten teachers participated in the pilot study. Comments and reviews of the participants were taken into account for the construction of the final phase questionnaire (https://docs.google.com/forms/d/e/1FAIpQLSdvAS0w3mG

\section{zIiRsLfDVw7oMnhXSKbZB7TbygN8s2IFEY9sg/viewfor} $\mathrm{m})$.

Research was conducted right after the lockdown period. Specifically, primary and secondary education schools were already re-opened and operating face-to-face for one and two weeks respectively, when the questionnaire was provided to the teachers. The questionnaire was created in the Google Forms environment and it was shared through emails and social media posts. The duration of the data collection process was one month.

The questionnaire consisted of three parts: the first one was related to the demographics of the participants ending with the question whether they were involved in distance education during the lockdown or not. Teachers involved in distance education were directed to the second part of the questionnaire. This part contained questions regarding their experience related to distance education. Teachers not involved in distance education were directed straight to the third part of the questionnaire. This part was addressed to all the participants and was related to their opinions for distance education in general (reasons for being involved or not, the type of support they needed, their view on the significance of distance education). In conclusion, parts 1 and 3 were addressed to all the participants $(1,120)$, while the second part was exclusively addressed to those that were involved in distance education $(1,077)$.

\section{B. Sample description}

1,120 teachers from primary and secondary education in Greece participated in the current research (Fig. 1). The majority $(833-74.4 \%)$ of them were female, reflecting the gender ratio of teachers in Greece. 62.1\% (696) hold a university degree, more than one third of the participants (389 - 34.7\%) hold a master's degree, while $3.1 \%$ of them (35) have a Ph.D. degree. Most of the participants (678 $60.5 \%$ ) were teaching in primary education schools and the remaining $39.5 \%$ (442) in secondary education schools. Participants from various scientific areas contributed to the research project: primary education teachers (339 - 30.3\%), kindergarden teachers $(169-15.1 \%)$, philologists (127 $11.3 \%$ ), foreign language (English, French, German) teachers $(129-11.6 \%)$ and computer science teachers (60 $5.4 \%$ ). The remaining $26.3 \%$ (296) regarded special education teachers, physical education teachers, technical education teachers, theologists, mathematicians, physicists, art teachers, sociology teachers, musicians, economists and theatrologists.

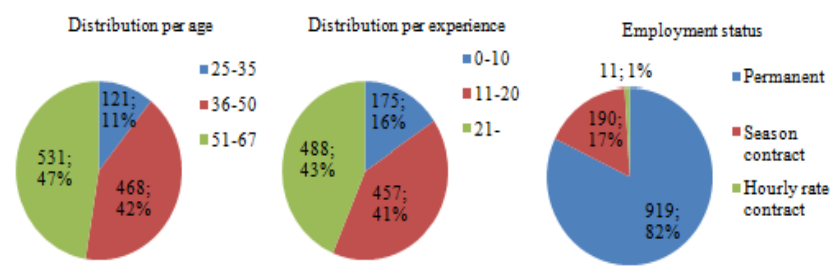

Fig. 1. Sample description.

Participants worked mainly in public schools (1,070 $95.5 \%$ ), while the rest $4.5 \%$ (50) worked in private schools. Teachers worked in town schools at a 56.6 rate (634). 17.6\% (197) worked in small town schools $(2,000-10,000$ inhabitants) and $25.8 \%$ (289) in village schools. 


\section{RESULTS}

Research results are available online at the following url: https://docs.google.com/forms/d/1IDqpxBYZmgnZwIHrI3fJ 1QmDr38R7QNpBTLie3OD mc/viewanalytics. Regarding internet use, $48.1 \%$ (539) of the participants used the internet for 3 to 5 hours per day, $39.6 \%$ (444) for 1 to 2 hours per day, while $6.9 \%$ (77) used the internet less than one hour per day and 5.4\% (60) used it occasionally (a few times per week). A significant percentage of $40.6 \%$ (455) had not any previous experience in distance education, $16 \%$ (179) had rarely used distance education applications, 14.2\% (159) had sometimes used them, 11.7\% (131) had often used them, while only $17.5 \%$ (196) had a great experience in distance education $(M=2.49, S D=1,53)$. Despite this lack of experience, Greek teachers used distance learning during the COVID-19 pandemic at a very high rate $(1,077$. $96.2 \%$ ). Specifically, $75.2 \%$ (810) used both synchronous and asynchronous applications, 21\% (226) used exclusively asynchronous applications and 3.8\% (41) used exclusively synchronous applications. Asynchronous distance education was frequently implemented, while synchronous distance education was occasionally used (Fig. 2).

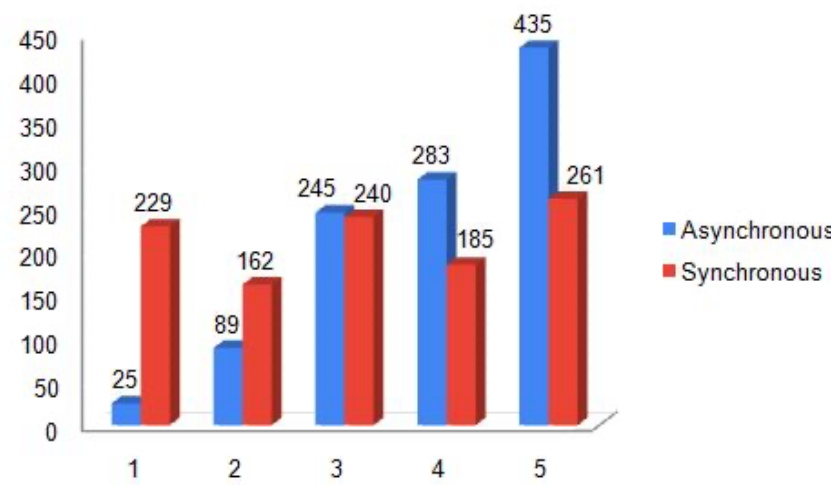

Fig. 2. Frequency per distance education type (1: never - 5: daily) - $M=$ 3.94, $S D=1.08$ (asynchronous), $M=3.08, S D=1.46$ (synchronous).

Transition to distance learning posed challenges and difficulties for the teachers, who additionally were not sufficiently satisfied with the interest and the participation of the students (Fig. 3). Despite this, they intend to use distance education in the future and characterized the relative experience as positive (Fig. 4,5$)$.

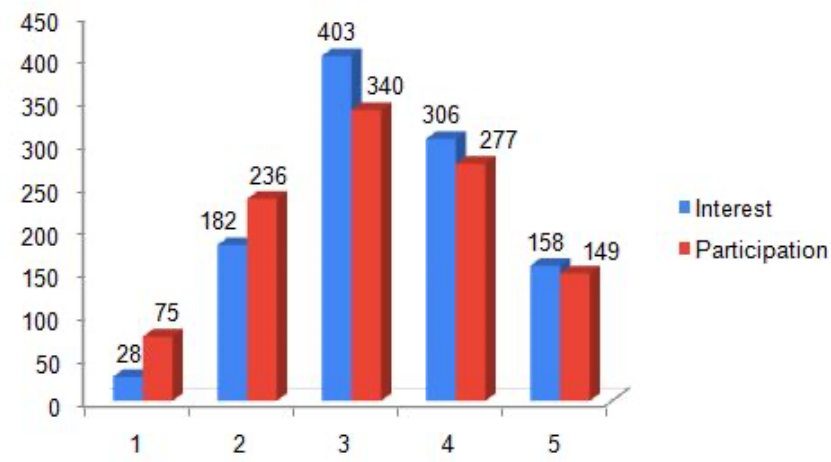

Fig. 3. Satisfaction of students' interest and participation (1: not at all - 2: very much) $-M=3.36, S D=1.01$ (interest), $M=3.18, S D=1.13$ (participation).

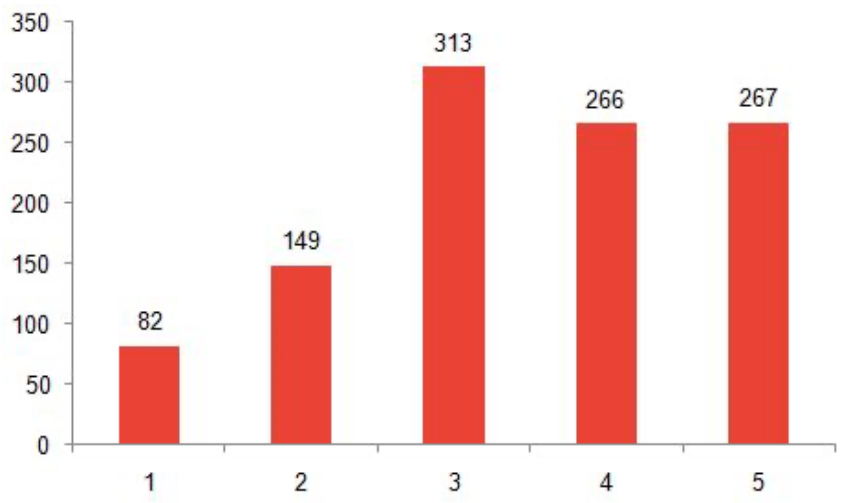

Fig. 4. Will you implement distance education in the future? (1: definitely not - 5: definitely) $(M=3.45, S D=1.22)$.

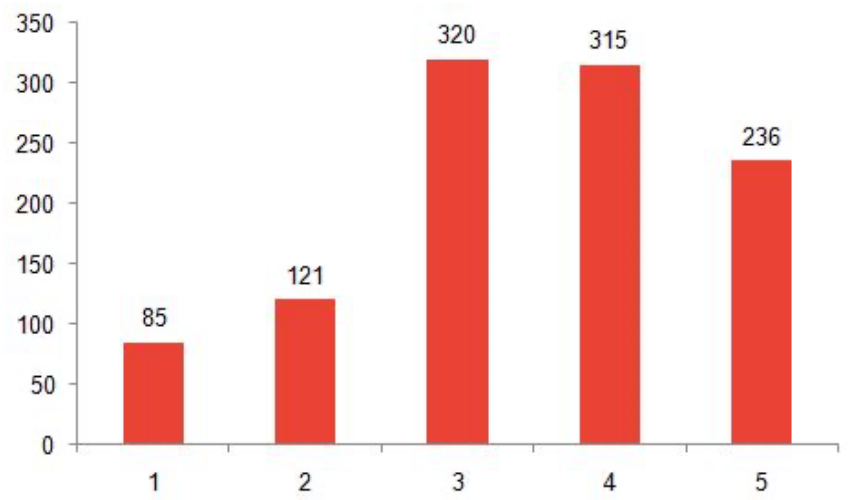

Fig. 5. Experience of distance education implementation (1: negative - 2: positive $)(M=3.46, S D=1.18)$.

Teachers were not satisfied with the support received during the implementation of distance education: $20 \%$ (215) were very unsatisfied, 26.6\% (287) unsatisfied, 26.9\% (290) considered the provided support as neutral, while $17.3 \%$ (186) were satisfied and only 9.2\% (99) were very satisfied $(M=2.69, S D=1.23)$. Regarding the provided support, teachers mentioned the virtual communities on the internet and the school support groups as their main support resources (Fig. 6).

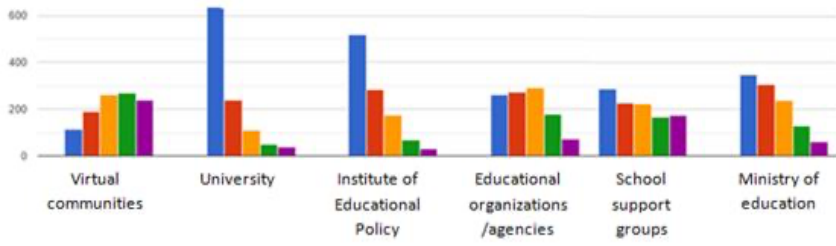

Fig. 6. Sources for material / support (1: not at all - 5: very much).

Technological capabilities of the distance learning applications were regarded as rather satisfactory by the teachers (Fig. 7). Overall, about half of them regarded distance education as important (Fig. 8).

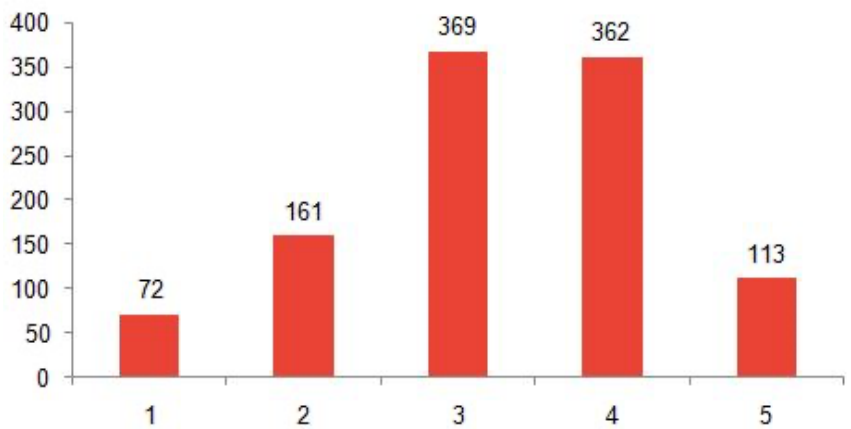

Fig. 7. Technological capabilities of distance education applications (1: very poor - 5 : excellent $)(M=3.26, S D=1.05)$. 


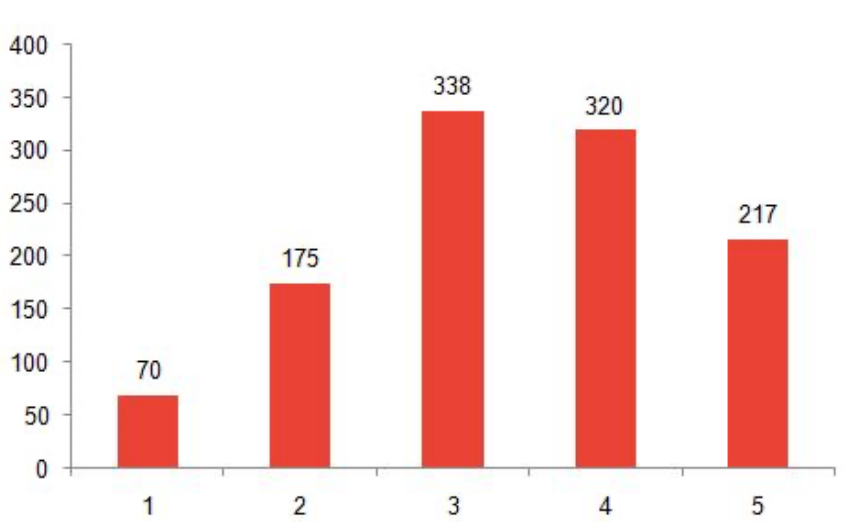

Fig. 8: Importance of distance education (1: unimportant - 5: very important) $(M=3.39, S D=1.15)$

\section{DISCUSSION}

A large number of primary and secondary education teachers in Greece $(1,120)$ coming from various academic areas participated in the current research, consisting a representative research sample. The majority of the teachers (589-52.6\%) were between 25 and 50 years old. These ages are expected to be familiar with ICT technologies. This is confirmed by the results revealing that $87.7 \%(1,060)$ of the teachers use the internet on a daily basis. Teachers were also very experienced, as $84.4 \%$ (945) had more than 11 years of teaching experience, whereas $43.6 \%$ (488) of the participants were highly experienced (more than 21 years of experience). Additionally, a significant percentage of $37.8 \%$ (424) had high academic skills, holding a master's or a Ph.D. degree.

Despite both their great experience and their familiarity with ICT technologies, $40.6 \%$ (455) of the teachers had no previous experience in distance education. This proved not to be an obstacle for them, as only $3.8 \%$ (43) did not implement distance education. It is important to notice that teachers implemented distance education at a very high rate (1,077-96.2\%), although it was not mandatory, neither for the teachers nor for the students. It is remarkable that $3.8 \%$ (41) used exclusively synchronous distance education applications, while $21 \% \quad$ (226) used exclusively asynchronous distance learning. This might be due to privacy matters or lack of equipment and infrastructure. In general, asynchronous distance education was more often used $(718-66.7 \%)$ compared to the synchronous (446 $41.4 \%)$.

Less than half of the teachers were satisfied from distance education, in terms of participation and interest. They mainly evaluated their experience as positive (551-51.1\%), while $19.1 \%$ (206) considered it as negative, and a significant rate of $29.7 \%$ (320) remained neutral. This experience is probably correlated with the support received: only $26.5 \%$ (285) appeared to be satisfied, while $46.6 \%$ (502) were dissatisfied with the provided support. Lack of satisfaction also existed for the technological capabilities of the applications used (475 - 44.1\% satisfied, $233-21.6 \%$ dissatisfied). Consecutively, $49.5 \%$ (533) stated that they intend to implement distance education in the future, while $21.4 \%$ (231) did not. In conclusion, Greek teachers appeared to be influenced by their experience during the COVID-19 pandemic, as 48\% (537) of them considered distance education important, while a significant rate of $21.9 \%$ (245) considered it not important.

\section{CONCLUSIONS AND FUTURE WORK}

Preliminary descriptive results of the current research revealed the experience of the teachers in Greece regarding distance education during the lockdown period in the COVID- 19 pandemic. Further in depth analysis will follow in the next steps of the research, exploring potential correlations between variables (gender, level of education, age, years of experience, working area) and the experience of the teachers, or potential differences between teachers (regarding implementation of distance education or not, use of exclusively synchronous or asynchronous applications, primary and secondary education, various scientific disciplines). Even though there were voices for the importance of distance education in case of a pandemic incident, the scale was not predicted. Post-pandemic research, now, will give us the time to design on a "digital pandemic" pedagogy.

\section{ACKNOWLEDGMENT}

To the 1,120 teachers participated in the present research.

\section{REFERENCES}

[1] B. Holmberg, H. Bernath, and F. W. Busch, The evolution, principles and practices of distance education. Bis, 2005, vol. 11.

[2] C. J. Bonk and C. R. Graham, The handbook of blended learning: Global perspectives, local designs. John Wiley \& Sons, 2012.

[3] Q. Liu, W. Peng, F. Zhang, R. Hu, Y. Li, and W. Yan, "The effectiveness of blended learning in health professions: Systematic review and meta-analysis," J Med Internet Res, vol. 18, no. 1, p. e2, Jan 2016. [Online]. Available: http://www.jmir.org/2016/1/e2/

[4] M. K. Khalil, E. M. Abdel Meguid, and I. A. Elkhider, "Teaching of anatomical sciences: A blended learning approach," Clinical Anatomy, vol. 31, no. 3, pp. 323-329, 2018. [Online]. Available: https://onlinelibrary.wiley.com/doi/abs/10.1002/ca.23052

[5] E. Lim, V. Oh, D.-R. Koh, and R. Seet, "The challenges of "continuing medical education" in a pandemic era," Ann Acad Med Singapore, vol. 38, no. 8, pp. 724-726, 2009.

[6] C. Jackson, E. Vynnycky, J. Hawker, B. Olowokure, and P. Mangtani, "School closures and influenza: systematic review of epidemiological studies," BMJ Open, vol. 3, no. 2, 2013. [Online]. Available: https://bmjopen.bmj.com/content/3/2/e002149

[7] C. Jackson, P. Mangtani, J. Hawker, B. Olowokure, and E. Vynnycky, "The effects of school closures on influenza outbreaks and pandemics: systematic review of simulation studies," PloS one, vol. 9 , no. 5 , p. e97297, 2014

[8] H. Rashid, I. Ridda, C. King, M. Begun, H. Tekin, J. G. Wood, and R. Booy, "Evidence compendium and advice on social distancing and other related measures for response to an influenza pandemic," Paediatric Respiratory Reviews, vol. 16, no. 2, pp. 119 - 126, 2015. [Online]. Available: http://www.sciencedirect.com/science/article/ pii/S1526054214000165

[9] L. Uscher-Pines, H. L. Schwartz, F. Ahmed, Y. Zheteyeva, E. Meza, G. Baker, and A. Uzicanin, "School practices to promote social distancing in k-12 schools: review of influenza pandemic policies and practices," BMC public health, vol. 18, no. 1, p. 406, 2018.

[10] A. Kanneganti, K. M. X. Lim, G. M. F. Chan, S.-N. Choo, M. Choolani, I. Ismail-Pratt, and S. J. S. Logan, "Pedagogy in a pandemic covid-19 and virtual continuing medical education (vcme) in obstetrics and gynecology," Acta Obstetricia et Gynecologica Scandinavica, vol. 99, no. 6, pp. 692-695, 2020. [Online].

Available: https://obgyn.onlinelibrary.wiley.com/doi/abs/10.1111/aogs.13885

[11] D. Moszkowicz, H. Duboc, C. Dubertret, D. Roux, and F. Bretagnol, "Daily medical education for confined students during coronavirus disease 2019 pandemic: A simple videoconference solution," Clinical 
Anatomy, vol. 33, no. 6, pp. 927-928, 2020. [Online]. Available: https://onlinelibrary.wiley.com/doi/abs/10.1002/ca.23601

[12] Z. I. Almarzooq, M. Lopes, and A. Kochar, "Virtual learning during the covid-19 pandemic: A disruptive technology in graduate medical education," Journal of the American College of Cardiology, vol. 75, no. 20, pp. 2635 - 2638, 2020. [Online]. Available:

http://www.sciencedirect.com/science/article/pii/S0735109720349172

[13] R. C. Chick, G. T. Clifton, K. M. Peace, B. W. Propper, D. F. Hale A. A. Alseidi, and T. J. Vreeland, "Using technology to maintain the education of residents during the covid-19 pandemic," Journal of Surgical Education, vol. 77, no. 4, pp. 729 - 732, 2020. [Online] Available:

http://www.sciencedirect.com/science/article/pii/S1931720420300842

[14] A. Abramson, "Enhancing online learning," Monitor on Psychology COVID19 special edition, vol. 51, no. 4, pp. 56 - 57, 2020. [Online]. Available: $\quad$ https://www.apa.org/monitor/2020/06/covid-onlinelearning

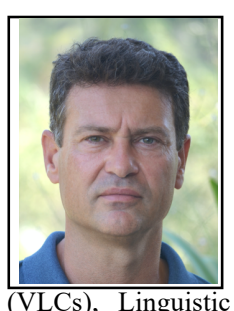

Stefanos Nikiforos graduated from the Department of Primary Education, University of the Aegean, in 1994. He received his M.Sc. in Informatics on Humanities from the Department of Informatics, Ionian University, in 2013. He received his Ph.D. Diploma in NLP for aggressive behavior detection in VLCs from the same department in 2020. His research interests include Natural Language Processing (NLP), Virtual Learning Communities (VLCs), Linguistic Data Mining, Computer Supported Collaborative

\section{Learning (CSCL), Machine Learning.}

Spyros Tzanavaris is a post-doc researcher in the School of Pastoral and Social Theology, at Aristotle University of Thessaloniki. Research interests are about Information and Communication Technology (ICT) in pedagogy and in culture.

Katia Lida Kermanidis graduated from the Electrical and Computer Engineering Department, University of Patras, in 1999. She received her PhD Diploma in Syntactic Dependencies' Learning from the same department in 2005. Her research interests include Artificial Intelligence, Natural Language Processing, Grammar Development, Information Retrieval, Linguistic Data Mining, Ontology Extraction. She has participated in, and scientifically coordinated European and Greek research projects in the areas of Computational Lexicography, Language and Speech processing, Corpus Processing, Machine Translation and Ontology Extraction. She was a member of the teaching staff of the Department of Informatics, Ionian University, from 2005 to 2009, and is an appointed Associate Professor at the Department since then. She has authored 16 journal articles and over 35 conference papers. She is a member of the Hellenic Artificial Intelligence Society (EETN). 